\title{
Article \\ Characterization of Chlamydomonas reinhardtii Mutants That Exhibit Strong Positive Phototaxis
}

\author{
Jun Morishita ${ }^{1,2}$, Ryutaro Tokutsu ${ }^{3,4,+}$, Jun Minagawa ${ }^{3,4} \oplus$, Toru Hisabori ${ }^{1,2}$ and Ken-ichi Wakabayashi $^{1,2, *}$ \\ 1 Laboratory for Chemistry and Life Science, Institute of Innovative Research, Tokyo Institute of Technology, \\ Yokohama 226-8503, Japan; senxiachunfalilv@gmail.com (J.M.); thisabor@res.titech.ac.jp (T.H.) \\ 2 School of Life Science and Technology, Tokyo Institute of Technology, Yokohama 226-8503, Japan \\ 3 Division of Environmental Photobiology, National Institute for Basic Biology, Okazaki 444-8585, Japan; \\ tokutsu.ryutaro.4e@kyoto-u.ac.jp (R.T.); minagawa@nibb.ac.jp (J.M.) \\ 4 Department of Basic Biology, Faculty of Life Science, The Graduate University for Advanced Studies, \\ SOKENDAI, Okazaki 444-8585, Japan \\ * Correspondence: wakaba@res.titech.ac.jp \\ + Current address: Department of Botany, Graduate School of Science, Kyoto University, \\ Kyoto 606-8502, Japan.
}

check for updates

Citation: Morishita, J.; Tokutsu, R.; Minagawa, J.; Hisabori, T.;

Wakabayashi, K.-i. Characterization of Chlamydomonas reinhardtii Mutants That Exhibit Strong Positive Phototaxis. Plants 2021, 10, 1483. https://doi.org/10.3390/plants 10071483

Academic Editors:

Tomoko Shinomura and Shun Tamaki

Received: 19 June 2021

Accepted: 15 July 2021

Published: 20 July 2021

Publisher's Note: MDPI stays neutral with regard to jurisdictional claims in published maps and institutional affiliations.

Copyright: (c) 2021 by the authors. Licensee MDPI, Basel, Switzerland. This article is an open access article distributed under the terms and conditions of the Creative Commons Attribution (CC BY) license (https:// creativecommons.org/licenses/by/ $4.0 /)$.

\begin{abstract}
The most motile phototrophic organisms exhibit photo-induced behavioral responses (photobehavior) to inhabit better light conditions for photosynthesis. The unicellular green alga Chlamydomonas reinhardtii is an excellent model organism to study photobehavior. Several years ago, we found that $C$. reinhardtii cells reverse their phototactic signs (i.e., positive and negative phototaxis) depending on the amount of reactive oxygen species (ROS) accumulated in the cell. However, its molecular mechanism is unclear. In this study, we isolated seven mutants showing positive phototaxis, even after the induction of negative phototaxis (ap1 7: always positive) to understand the ROS-dependent regulatory mechanism for the phototactic sign. We found no common feature in the mutants regarding their growth, high-light tolerance, and photosynthetic phenotypes. Interestingly, five of them grew faster than the wild type. These data suggest that the ROS-dependent regulation of the phototactic sign is not a single pathway and is affected by various cellular factors. Additionally, the isolation and analyses of mutants with defects in phototactic-sign regulation may provide clues for their application to the efficient cultivation of algae.
\end{abstract}

Keywords: Chlamydomonas; phototaxis; photosynthesis; photoprotection

\section{Introduction}

For motile phototrophic organisms, photo-induced behavioral responses (photobehavior) are important to maintain optimal light exposure for their photosynthetic activities. The unicellular green alga Chlamydomonas reinhardtii is an ideal model organism for studying photo responses because it exhibits striking photobehavior immediately after photoreception [1,2]. The typical photobehavior in C. reinhardtii includes phototaxis and photoshock response. Phototaxis is a behavior in which cells swim toward or away from incident light (called positive or negative phototaxis, respectively). Photoshock response is a behavior in which cells stop swimming or swim backward for a short period after a sudden change in light intensity.

Both behaviors are regulated by the following two organelles: the eyespot and cilia. The eyespot is a directional photoreceptive organelle [3,4]. The eyespot constitutes two parts, namely, the carotenoid-granule layers (CGLs) and the photoreceptor protein channel rhodopsins (ChRs). The CGLs function as a quarter-wave stack and reflect light [5-7]. These layers line ChRs in the plasma membrane. ChRs function as cation channels upon photoreception [8-10]. Due to the light reflection at the CGLs, ChRs sense light only when illuminated from the eyespot side. Cellular $\mathrm{Ca}^{2+}$ concentration is suggested to be 
modulated by photoreception. $\mathrm{Ca}^{2+}$-sensitivities of the two cilia are distinct: the cis-cilium, closest to the eyespot, beats stronger than the other when $\left[\mathrm{Ca}^{2+}\right]_{\mathrm{i}}<\sim 10^{-7} \mathrm{M}$, and the trans-cilium, the other one, beats stronger than the other when $\left[\mathrm{Ca}^{2+}\right]_{\mathrm{i}}>\sim 10^{-7} \mathrm{M}$ [11]. By this regulation, the forces generated by the two cilia become imbalanced, and the cell changes its swimming direction to exhibit phototaxis.

How, then, do cells reverse their phototactic sign (or direction)? Several signals have been reported to regulate the phototactic signs, such as photosynthetic activity, circadian rhythm, and light intensity [12-14]. Among these signals, the cellular reactive oxygen species (ROS) level strongly affects the phototactic sign. After treatment with membranepermeable ROS reagents, cells show positive phototaxis, whereas after treatment with membrane-permeable ROS-scavenging reagents, cells show negative phototaxis [15]. Even the negatively phototactic strain agg1 (a wild-type strain CC-124) shows positive phototaxis after treatment with ROS, suggesting that the ROS signal can override other effects [16].

However, this ROS-dependent sign switching of phototaxis is contradictory. ROS is a hazardous byproduct of photosynthesis [17]. Light energy higher than the level that saturates photosynthetic reactions produces excess reductive power, producing ROS. ROS damages various essential cellular materials, including proteins and lipids, and thus, phototrophic organisms have different defense mechanisms against ROS [18]. If $C$. reinhardtii cells show positive phototaxis when the cellular ROS amount increases, the light intensity may increase, and more ROS would be produced; this seems like a suicide. Simultaneously, the induction of positive phototaxis by ROS is highly reproducible $[7,16,19,20]$.

The questions that arise are how and why $C$. reinhardtii cells show ROS-dependent positive phototaxis. For answering these questions, forward genetics will be a strong strategy because the molecular basis for this pathway is difficult to predict. This study introduced random mutations to wild-type $C$. reinhardtii to screen for mutants showing positive phototaxis, even after treatment with ROS scavengers that induce negative phototaxis. Phenotypic analyses of the mutants suggested that the molecules affecting the phototaxis pathways vary.

\section{Results}

\subsection{Mutant Screening for Phototactic Signs}

To generate mutants with defects in the pathways that regulate phototaxis in an ROS-dependent manner, we induced random insertional mutagenesis to wild-type (WT) C. reinhardtii using a paromomycin-resistant vector (pSI103-1) [21]. After selection with paromomycin, the mutant library was subjected to phototaxis screening (Figure 1A). Usually, WT cells show negative phototaxis after treatment with membrane-permeable ROSscavenging reagents such as dimethylthiourea (DMTU) or TEMPOL [15] (Figure 1B,C). We treated the mutagenized cells with DMTU and then screened for mutants showing positive phototaxis (Figure 1A). We repeated this screening twice against seven independent mutant libraries, isolating one mutant from each library that showed positive phototaxis after treatment with DMTU. After backcrossing the mutants with WT twice, we named them ap (always positive phototaxis) 1 7.

On the basis of the results of the phenotypic analysis described later, we selected ap2 and ap 7 for more detailed phototaxis analysis. In light conditions where the parental WT strain cells tended to show negative phototaxis, both the ap2 and ap7 cells showed positive phototaxis. DMTU induced negative and $t-\mathrm{BOOH}$, a membrane-permeable ROS reagent, induced positive phototaxis in WT cells (Figure 1C) [15]. DMTU sufficiently induced negative phototaxis at $75 \mathrm{mM}$ in the WT cells, but even after treatment with $150 \mathrm{mM}$ DMTU, the ap2 and ap7 cells showed positive phototaxis (Figure 1C).

After the backcross, the phenotypic and genotypic analyses showed that the progenies containing an insertion of the pSI103-1 vector did not always show an ap phenotype (Figure S1). These data suggest that the ap phenotypes of all seven mutants were caused by the insertion of short DNA fragments derived from the vectors or genomic DNA of dead 
cells during electroporation. Therefore, the causative genes of ap1 7 could not be easily traced at this moment.
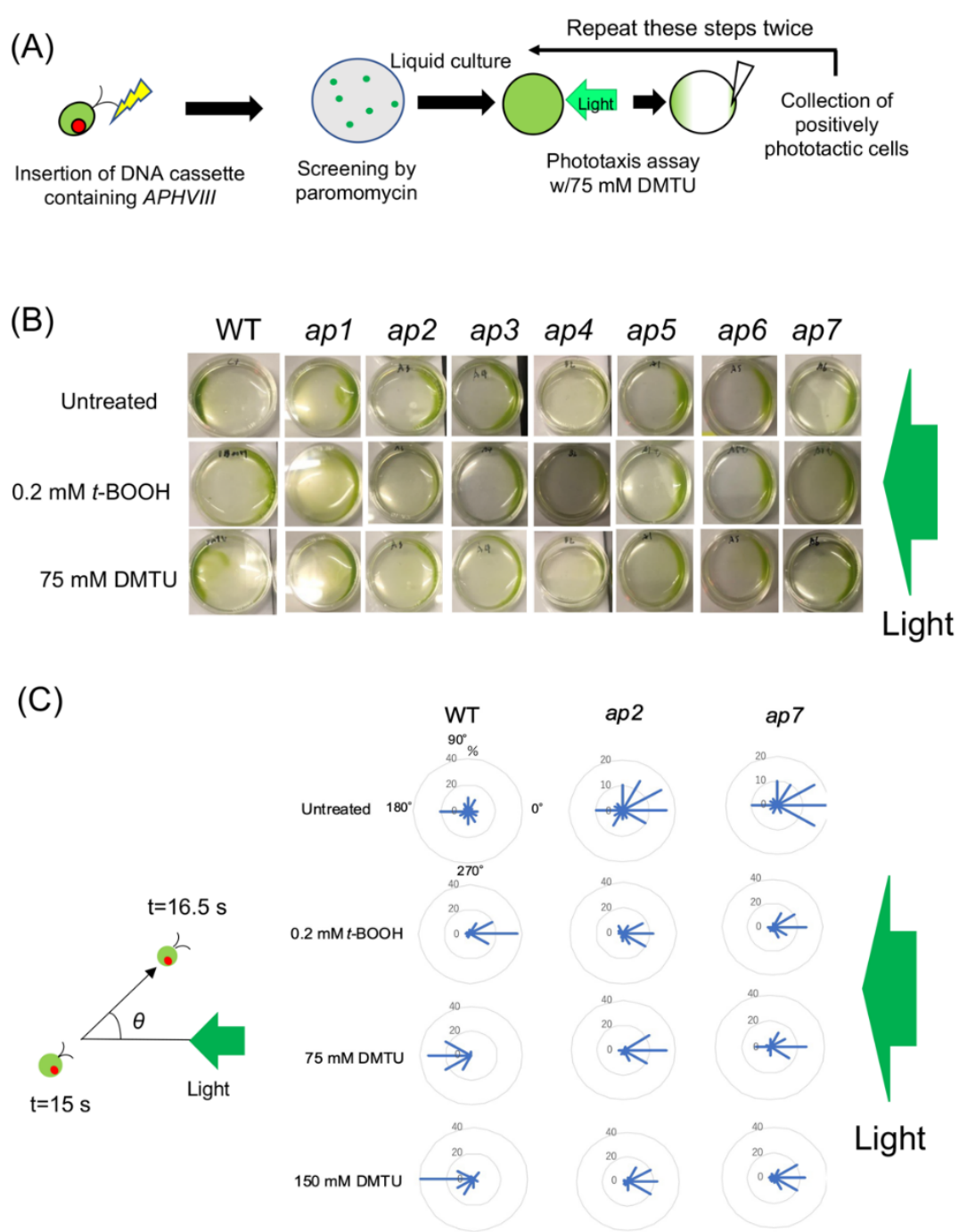

Figure 1. Isolation of ap mutants. (A) Schematics showing the screening methods for ap mutants. After introducing the pSI103-1 vector containing the APHVIII gene that confers paromomycin resistance, transformants were inoculated onto the selection agar plate. After collecting colonies, transformant cells (a mutant library) were subjected to phototaxis assay after treatment with $75 \mathrm{mM}$ DMTU that strongly induces negative phototaxis. Cells showing positive phototaxis were collected, cultured again, and subjected to the second phototaxis assay. A mutant constantly showing positive phototaxis was isolated from a library and named ap mutant. (B) Phototaxis of WT and ap mutant cells. Cells were put in a Petri dish, and green light was illuminated from the right side. WT cells showed negative phototaxis without any treatment, positive phototaxis after treatment with $0.2 \mathrm{mMt} t \mathrm{BOOH}$, and negative phototaxis after treatment with DMTU. The ap mutants showed positive phototaxis in any condition. (C) (Left) Schematic of cell-level phototaxis assay. Cell swimming angle ( $\theta$ ) was measured for $1.5 \mathrm{~s}$ following $15 \mathrm{~s}$ of illumination with a green LED. (Right) Cell-level phototaxis assay of WT and representative ap mutants, ap 2 and ap7. Polar histograms depicting the percentage of cells moving in a particular direction relative to light illumination from the right $\left(12\right.$ bins of $30^{\circ} ; \mathrm{n}=30$ cells per condition). Cells were observed after treatment with no reagent (top), $0.2 \mathrm{mM} t$-BOOH to induce positive phototaxis (second from the top), $75 \mathrm{mM}$ (third from the top), or $150 \mathrm{mM}$ DMTU to induce negative phototaxis (bottom). 


\subsection{Morphology and Motility of ap Mutants Are Normal}

To analyze which pathway affects ROS-dependent phototaxis regulation, we examined several phenotypes of ap mutants other than phototaxis. First, we tested the morphology and motility of these mutant cells. The cell size (diameter approximated as a sphere), ciliary length, and ciliary beating frequency were measured (Table 1). In each parameter, there was no significant difference between the strains, including WT.

Table 1. Morphological and motility phenotypes of ap mutants.

\begin{tabular}{|c|c|c|c|c|c|c|c|c|}
\hline & WT & ap1 & $a p 2$ & ap3 & ap4 & ap5 & ap6 & $a p 7$ \\
\hline Cell size $(\mu \mathrm{m}) *$ & $7.5 \pm 0.1$ & $7.0 \pm 0.1$ & $7.1 \pm 0.2$ & $7.3 \pm 0.3$ & $7.0 \pm 0.1$ & $7.0 \pm 0.2$ & $6.9 \pm 0.1$ & $7.4 \pm 0.1$ \\
\hline $\begin{array}{l}\text { Ciliary length } \\
(\mu \mathrm{m})^{* *}\end{array}$ & $13.2 \pm 1.5$ & $13.9 \pm 1.6$ & $13.6 \pm 1.7$ & $13.2 \pm 1.6$ & $13.7 \pm 2.0$ & $13.6 \pm 1.6$ & $13.3 \pm 1.5$ & $13.5 \pm 1.4$ \\
\hline $\begin{array}{l}\text { Ciliary beating } \\
\text { frequency }(\mathrm{Hz})^{*}\end{array}$ & $57.4 \pm 0.5$ & $56.0 \pm 1.6$ & $57.4 \pm 1.1$ & $56.1 \pm 2.0$ & $59.0 \pm 0.6$ & $53.1 \pm 1.1$ & $55.2 \pm 1.2$ & $54.7 \pm 1.3$ \\
\hline
\end{tabular}

No significant difference between any two groups was found in each parameter $(p>0.05$, one-way ANOVA and Tukey's honest significance difference (HSD)). * Mean \pm S.E.M. of three independent experiments, ${ }^{* *}$ mean \pm S.D. of 20 cilia.

Next, we examined the growth rate under normal light conditions (white light, $\sim 30 \mu \mathrm{mol}$ photons $\left.\mathrm{m}^{-2} \mathrm{~s}^{-1}\right)$. Interestingly, five of the seven ap mutants showed faster growth than WT (Figure 2).

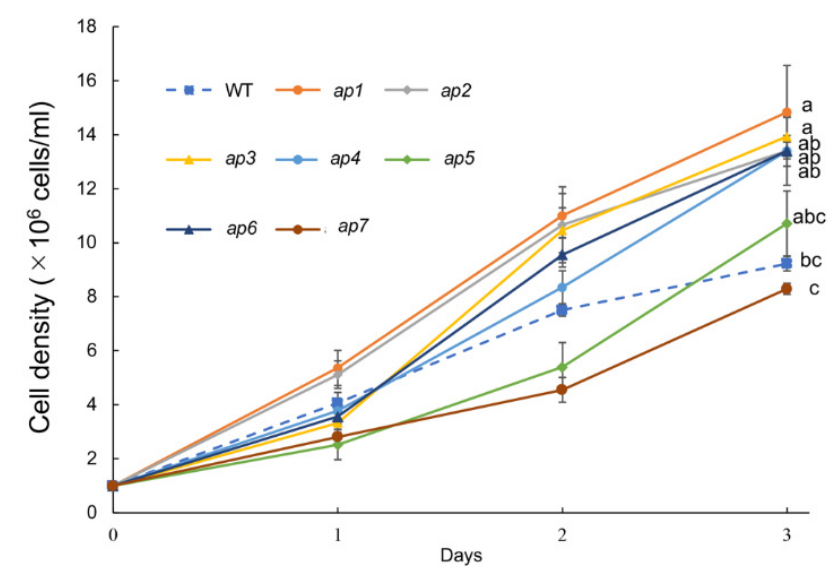

Figure 2. The growth phenotype of ap mutants. Precultured cells were collected and suspended in a fresh medium at $1 \times 10^{6}$ cells $/ \mathrm{mL}$ (day 0 ) and subjected to culture under $30 \mu \mathrm{mol}$ photons $\mathrm{m}^{-2} \mathrm{~s}^{-1}$ white light. Cell density was measured every day and means \pm S.E.M. $(n=3)$ are shown. Different letters indicate significant differences $(p<0.05$, one-way ANOVA and Tukey's honest significance difference (HSD)).

These results were somewhat surprising. We assumed that ROS accumulation is more significant in the ap mutant cells than in WT because of the effects of ROS-scavenger treatment on the phototactic sign, which were inhibited in these mutants. ROS accumulation may be hazardous to the cells, and treatment with ROS decreases the ciliary beating frequency of C. reinhardtii [22]. Contrary to these expectations, many ap strains showed high growth rates, suggesting that increased intracellular ROS levels are not directly responsible for the ap phenotype.

\subsection{Photosynthesis Phenotypes of ap Mutants}

We then measured photosynthesis-related parameters such as chlorophyll content, photosynthetic efficiency ( $\varphi \mathrm{II})$, and nonphotochemical quenching (NPQ) (Table 2). However, again, there were no significant differences between the strains in each parameter. We also measured survivability under high-light stress conditions. The cells were treated 
using low light (white, $50 \mu \mathrm{mol}$ photons $\mathrm{m}^{-2} \mathrm{~s}^{-1}$ ) or high light (white, $1000 \mu \mathrm{mol}$ photons $\mathrm{m}^{-2} \mathrm{~s}^{-1}$ ). The results suggested that ap1 and ap 7 had a slightly weaker high-light tolerance than WT (Figure 3).

Table 2. Photosynthesis-related phenotypes of ap mutants.

\begin{tabular}{|c|c|c|c|c|c|c|c|c|}
\hline & WT & ap1 & $a p 2$ & ap3 & ap4 & ap5 & ap6 & $a p 7$ \\
\hline $\begin{array}{l}\text { Chlorophyll } \\
\text { (pg/cell)* }\end{array}$ & $0.78 \pm 0.10$ & $0.73 \pm 0.13$ & $0.82 \pm 0.05$ & $0.75 \pm 0.07$ & $0.83 \pm 0.06$ & $0.81 \pm 0.14$ & $0.70 \pm 0.05$ & $0.97 \pm 0.07$ \\
\hline $\begin{array}{l}\text { Photosynthetic } \\
\text { efficiency } \\
(\varphi \mathrm{II})^{* *}\end{array}$ & $0.59 \pm 0.01$ & $0.61 \pm 0.02$ & $0.59 \pm 0.01$ & $0.59 \pm 0.02$ & $0.57 \pm 0.01$ & $0.58 \pm 0.02$ & $0.59 \pm 0.02$ & $0.57 \pm 0.01$ \\
\hline $\mathrm{NPQ}^{* *}$ & $0.30 \pm 0.02$ & $0.30 \pm 0.02$ & $0.31 \pm 0.01$ & $0.29 \pm 0.04$ & $0.29 \pm 0.03$ & $0.28 \pm 0.01$ & $0.29 \pm 0.01$ & $0.28 \pm 0.01$ \\
\hline
\end{tabular}

$300 \mu \mathrm{mol}$ photons $\mathrm{m}^{-2} \mathrm{~s}^{-1}$ white light was irradiated as actinic light. No significant difference between any two groups was found in each parameter $\left(p>0.05\right.$, one-way ANOVA and Tukey's honest significance difference (HSD)). ${ }^{*}$ Mean \pm S.E.M. of four independent experiments, ${ }^{* *}$ mean \pm S.E.M. of three independent experiments.

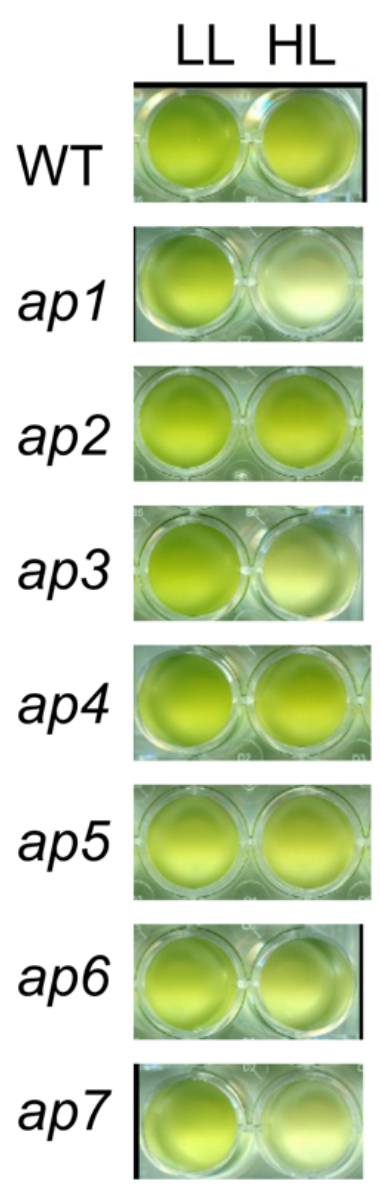

Figure 3. High-light tolerance of ap mutants. Cells were grown under low light (LL; white, $50 \mu \mathrm{mol}$ photons $\mathrm{m}^{-2} \mathrm{~s}^{-1}$ ) or high light (HL; white, $1000 \mu \mathrm{mol}$ photons $\mathrm{m}^{-2} \mathrm{~s}^{-1}$ ) for $18 \mathrm{~h}$. A 70-microliter aliquot was put in a well of a 96-well plate.

Summarizing the results thus far, phenotypes in ap1 7 other than positive phototaxis after treatment with DMTU are not necessarily consistent. Most of them grew faster than WT, but not all. There were no significant differences from WT in the photosynthetic parameters. Two of the mutants seemed to exhibit a weaker high-light tolerance than WT. 


\subsection{Detailed Photosynthesis Phenotype Analyses of ap2 and ap7}

In the photosynthesis analyses above, we fixed the light conditions to assess the seven mutants simultaneously. For detailed analyses, we selected ap2 and ap7. Ap2 represents the strains with higher-growth than WT (Figure 2), and ap7 represents the strains with lower-growth than WT (Figure 3). We treated the cells with low light or high light before the analyses using a pulse amplification modulation and measured the photosynthetic parameters under various light intensities. The values of $\varphi$ II and NPQ change in almost the same manner among the strains (Figure 4A,B). In contrast, both ap 2 and ap 7 showed a lower ETR than WT when pretreated with low light and measured using high light (Figure 4C). Furthermore, only ap7 showed a lower ETR than WT when pretreated with high light (Figure 4C).

(A)

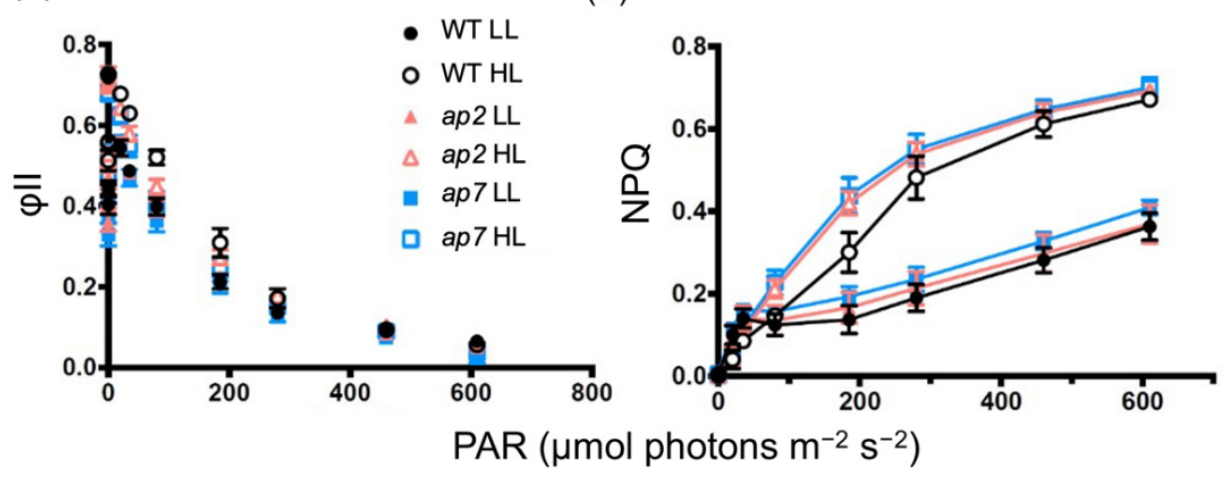

(C)

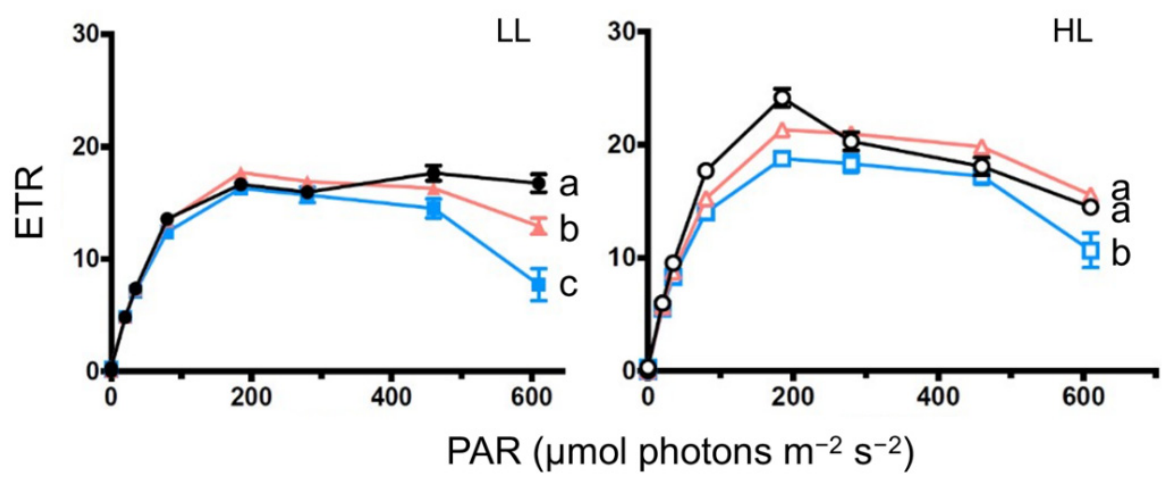

Figure 4. Photosynthetic parameters of ap2 and ap7 after treatment with low or high light. (A) $\varphi \mathrm{II}$, (B) NPQ, and (C) ETR of WT, ap2, and ap7 cells after treatment with low light (LL; white, 50 umol photons $\mathrm{m}^{-2} \mathrm{~s}^{-1}$ ) or high light (HL; white, $1000 \mu$ mol photons $\left.\mathrm{m}^{-2} \mathrm{~s}^{-1}\right)(\mathrm{n}=3$, mean \pm S.E.M.). In (C), different letters indicate significant differences $(p<0.05$, one-way ANOVA and Tukey's honest significance difference (HSD)). PAR: photosynthetically active radiation.

Next, we examined the high-light tolerance of ap 2 and ap 7 under $700 \mu \mathrm{mol}$ photons $\mathrm{m}^{-2} \mathrm{~s}^{-1}$ red light or $300 \mu \mathrm{mol}$ photons $\mathrm{m}^{-2} \mathrm{~s}^{-1}$ blue light. The former conditions induce a slow and the latter conditions cause a fast induction of NPQ [23,24]. Under high red light, similar to the white-light conditions (Figure 3), ap2 showed a slightly higher and ap7 showed a slightly lower tolerance than WT (Figure 5A,B). In contrast, under high blue light, ap2 and ap7 showed an almost comparable tolerance to WT (Figure 5A,B). With the data showing that mutants exhibit normal NPQ (Figure 4), the difference in high-light tolerance in ap2 and ap7 may not be due to NPQ. 
(A)

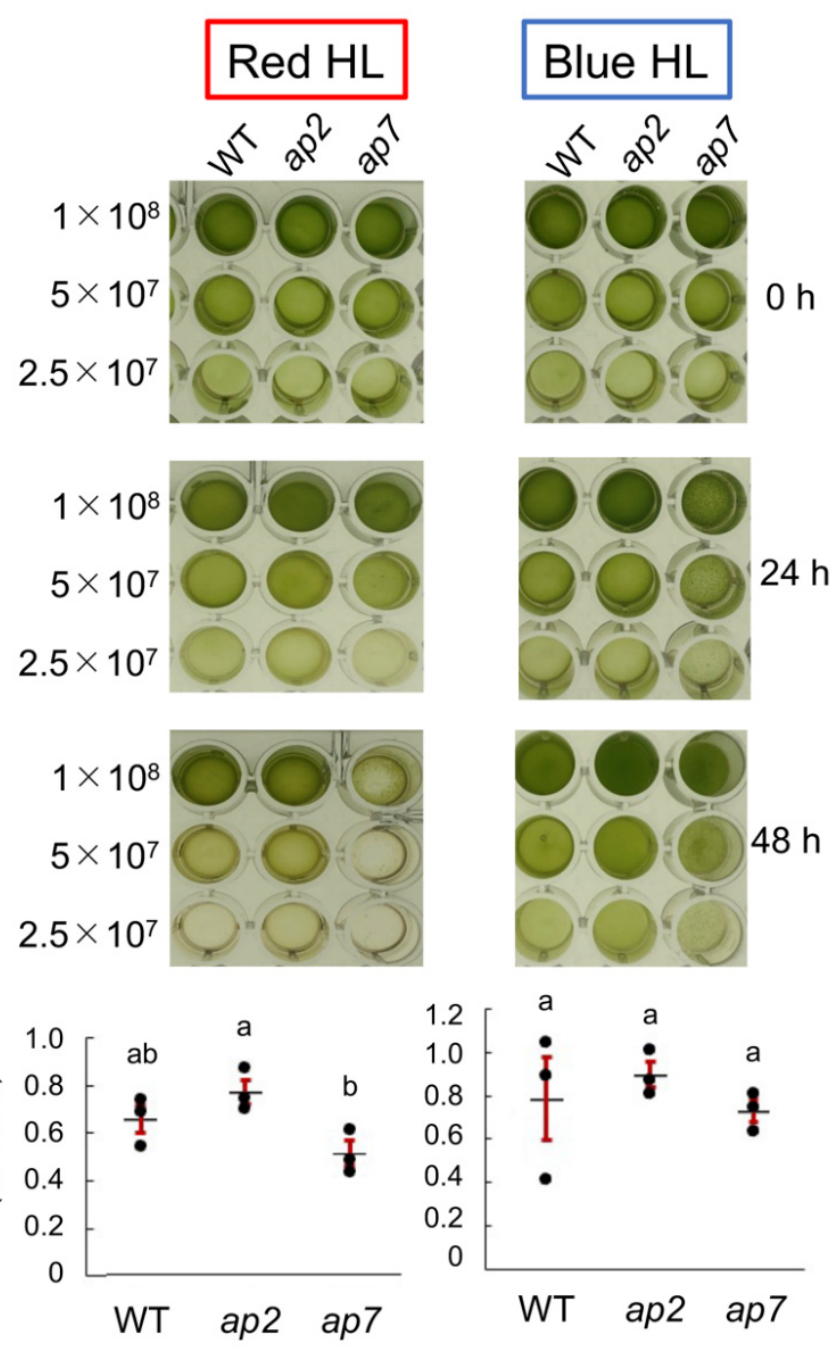

Figure 5. High-light tolerance of ap2 and ap7 under red or high blue light. (A) Dilution series of WT, ap2, and ap 7 cell culture $\left(2.5 \times 10^{7}-1 \times 10^{8}\right.$ cells $\left./ \mathrm{mL}\right)$ were illuminated with either red high light (left; $\lambda=640 \mathrm{~nm}, 800 \mu \mathrm{mol}$ photons $\mathrm{m}^{-2} \mathrm{~s}^{-1}$ ) or blue high light (right; $\lambda=470 \mathrm{~nm}, 300 \mu \mathrm{mol}$ photons $\mathrm{m}^{-2}$ $\mathrm{s}^{-1}$ ) for two days. (B) The density of each well was measured, and the ratio of the value at $48 \mathrm{~h}$ per that at $0 \mathrm{~h}$ was calculated. Each dot represents the individual result, and mean values (black bars) \pm S.E.M. (red bars) $(\mathrm{n}=3)$ are shown. Different letters indicate significant differences $(p<0.05$, one-way ANOVA and Tukey's honest significance difference (HSD)).

\section{Discussion}

In this study, to understand the mechanisms underlying the ROS-dependent regulation of the phototactic sign in C. reinhardtii, we isolated new mutants ap1 7 showing positive phototaxis, even after negative phototaxis by a ROS-scavenger DMTU. However, the causative genes of these mutants could not be traced at this moment because the insertion of the generated vectors did not cause ap phenotypes. Instead, we characterized these mutants in various ways.

\subsection{Phenotypic Discrepancy among ap Mutants}

Unexpectedly, the phenotypes of the ap mutants were not completely consistent. As for the growth rate, $a p 1$ and ap 3 were significantly faster, and ap 7 was slightly slower than WT (Figure 2). As for the red high light tolerance, ap 2 was slightly higher and ap 7 was slightly lower than WT (Figure 5). From their common positive-phototaxis phenotype, we assumed that all ap mutant cells might accumulate higher levels of ROS, and $75 \mathrm{mM}$ DMTU is not enough to quench them. If all mutants accumulate high ROS levels, some 
phenotypes would be shared, such as a low tolerance of high light, slow growth, and low ciliary beating frequency $[22,25,26]$, but our data showed that the ap mutants did not share such phenotypes commonly. These data suggest that the reasons to show an ap phenotype are variable and complex. The function of ROS or ROS scavengers in the phototaxis pathway is still unknown. ROS generation, ROS quenching, and ROS sensing pathways in the cell may be involved in this regulation, and further genetic analysis of ap mutants will provide clues to which proteins play essential roles in the ROS-dependent phototactic-sign regulation mechanisms.

\subsection{Growth Phenotype}

Notably, five of the seven ap mutants showed a significantly faster growth than WT (Figure 2). It has been reported that $C$. reinhardtii mutants that have acquired resistance to singlet oxygen by gain-of-function mutations that grow faster than wild-type strains under oxidative stress conditions [27]. Such mutations may occur in fast-growing ap mutants. Recently, microalgae, including C. reinhardtii, have attracted attention as a platform for producing valuable materials [28]. Further analyses to clarify how the ap phenotype and fast-growing phenotype are linked will contribute to the application for the improvement in microalgae cultivation.

\subsection{High-Light Tolerance}

In plants and algae, photoprotective mechanisms are activated under high-light conditions, in which ROS-scavenging or excitation-energy-dissipation systems protect cells from photodamage $[29,30]$. The $C$. reinhardtii mutants lacking these photoprotective systems exhibit a significantly lower tolerance against high light than WT [31,32]. Both the ap2 and ap7 strains showed a similar level of tolerance to the wild-type strain under blue highlight conditions, which rapidly induce NPQ through the expression of LHCSR proteins (Figure 5) [23]. Alternatively, under red light conditions, ap2 and ap7 showed a slightly higher and lower light tolerance, respectively (Figure 5). The LHCSR protein expression level is lower in red light than in blue light, which leads to lower NPQ [33]. Thus, ap7 may have defects in photoprotection pathways other than NPQ, correlated with lower ETR under high-light conditions and a lower-growth rate (Figures 2 and 4D).

\section{Conclusions}

We isolated new mutants showing positive phototaxis after the induction of negative phototaxis (ap1 7). Though we expected that these mutant cells contain higher ROS levels than WT, five of them showed higher-growth phenotypes without significant morphological, motility-related, or photosynthetic phenotypes. The absence of phenotypes other than phototaxis common to the seven mutants suggests the diversity of the biological parameters involved in the ROS-dependent regulation of phototaxis. Further genetic analyses of the mutants will shed light on the enigmatic ROS-dependent phototaxis regulation.

\section{Materials and Methods}

\subsection{Cell Culture and Strains}

Chlamydomonas reinhardtii strains CC-124 (nit1 - (nitrate reductase), nit2-, agg1-, and $\mathrm{mt}-$ (mating type) [16] and CC-125 (nit1 - , nit2-, and $\mathrm{mt}+$ ) were used. For the elimination of agg1 mutation, agg1+ progenies ( $\mathrm{mt}+$ and $\mathrm{mt}-$ ) from the mating of CC-124 and CC-125 were used as wild-type. Cells were grown in a tris-acetate phosphate medium (TAP) medium with aeration at $25^{\circ} \mathrm{C}$ on a $12 \mathrm{~h} / 12 \mathrm{~h} \mathrm{light/dark} \mathrm{cycle} \mathrm{[34].} \mathrm{For} \mathrm{the} \mathrm{photosynthetic}$ parameter measurement, cells were collected after culturing in TAP medium, resuspended in high-salt (HS) minimal medium [35], and grown under the same light conditions as above without aeration for one day. 


\subsection{Mutagenesis and Screening for ap Mutants}

Wild-type (mt-) cells were mutagenized by the random insertion of pSI103-1 vector (linearized by EcoRI) that confers paromomycin resistance via electroporation (NEPA21, NEPAGENE) [21,36]. After collecting colonies on the selection agar plates, those cells (a mutant library) were subjected to the phototaxis assay after treatment with $75 \mathrm{mM}$ DMTU (Sigma-Aldrich), which strongly induces negative phototaxis [15]. After green light illumination $\left(\lambda=525 \mathrm{~nm}, 30 \mu \mathrm{mol}\right.$ photons $\left.\mathrm{m}^{-2} \mathrm{~s}^{-1}\right)$, cells showing positive phototaxis were collected. After culturing those mutant candidates for a few days, the same phototaxis assay was repeated. Cells showing positive phototaxis were inoculated onto a TAP agar plate, and grown single colonies were inoculated independently in a TAP medium in a 96-well scale. Cultures were subjected to the phototaxis assay again, and a strain showing positive phototaxis after the DMTU treatment was selected as an ap mutant. These assays were conducted against seven mutant libraries.

\subsection{Cell-Level Phototaxis Assay}

Cell-level phototactic motion was tracked based on a previously described method [15] with modifications. Briefly, cells were washed with experimental practical solution $(5 \mathrm{mM}$ Hepes (pH 7.4), $0.2 \mathrm{mM}$ EGTA, $1 \mathrm{mM} \mathrm{KCl}$, and $0.3 \mathrm{mM} \mathrm{CaCl}_{2}$ ) with or without treatment with DMTU or $t$-BOOH (FUJIFILM Wako Pure Chemical Corporation, Osaka, Japan) and kept under dim red light for $15 \mathrm{~min}$ before the phototaxis assays. The behavior of the cells was observed and video-recorded under a dark-field microscope (BX-53, Olympus) with dim red light under unidirectional illumination using a green light-emission diode $\left(\lambda=525 \mathrm{~nm}, 30 \mu \mathrm{mol}\right.$ photons $\left.\mathrm{m}^{-2} \mathrm{~s}^{-1}\right)$. The angle $(\theta)$ between the light direction and the swimming direction was measured during $1.5 \mathrm{~s}$, following illumination with a green LED for $15 \mathrm{~s}$. Images of swimming cells were auto-tracked using Image Hyper software (Science Eye). The angles were calculated from the cell trajectories.

\subsection{Ciliary Beating Frequency Measurement}

Ciliary beating frequency was measured based on a previously described method [37] with modifications [22]. Briefly, a photodetector was set on the top of a microscope equipped with a dark-field condenser (BX-53; Olympus). Cells were observed under a microscope with a dim red light $(\lambda>630 \mathrm{~nm})$ to avoid the accumulation of cells caused by phototaxis. The photodetector detected signals derived from cell body vibration, transferred to the computer soundboard, and fast-Fourier transformed using SIGVIEW (SignalLab). Transformed signals were averaged for $\sim 20 \mathrm{~s}$, and the peak value was regarded as the mean ciliary beating frequency.

\subsection{Cell Density and Cell Size Measurement}

Cell culture was mixed with an equal volume of deciliation solution $\left(1 \mathrm{mM} \mathrm{CaCl}_{2}\right.$ and $40 \mathrm{mM}$ sodium acetate). Cell density was measured using an automatic cell counter (model R-1, Olympus, or Cell Drop BF, DeNovix). Additionally, the cell size (diameter when a cell is approximated to a sphere) was simultaneously measured using the same cell counter.

\subsection{Growth Rate Assay}

Cells were grown in the TAP medium for three days under $30 \mu \mathrm{mol}$ photons $\mathrm{m}^{-2} \mathrm{~s}^{-1}$ white light, adjusted to $1 \times 10^{6}$ cells $/ \mathrm{mL}$ in a fresh TAP medium (day 0 ), and then grown again under the same light conditions. The cell density of each strain was measured every day as described above.

\subsection{Chlorophyll Amount Measurement}

Cell culture was collected and resuspended in an HS medium, and cell density was measured. Cell suspension $(200 \mu \mathrm{L})$ and acetone $(800 \mu \mathrm{L})$ were mixed using a vortex mixer and spun down, and $\mathrm{Abs}_{750}, \mathrm{Abs}_{663.6}$, and $\mathrm{Abs}_{646.6}$ of the supernatants were measured. Chlorophyll contents were calculated according to the equations shown in [38]. 


\subsection{High-Light Tolerance Assay}

A 700-microliter culture in HS medium was placed in a microtube and illuminated with low light (white, $50 \mu \mathrm{mol}$ photons $\mathrm{m}^{-2} \mathrm{~s}^{-1}$ ) or high light (white, $1000 \mu \mathrm{mol}$ photons $\left.\mathrm{m}^{-2} \mathrm{~s}^{-1}\right)$ for $18 \mathrm{~h}$ (Figure 2), or with red light $\left(\lambda=640 \mathrm{~nm}, 800 \mu \mathrm{mol}\right.$ photons $\left.\mathrm{m}^{-2} \mathrm{~s}^{-1}\right)$ or blue light $\left(\lambda=470 \mathrm{~nm}, 300 \mu \mathrm{mol}\right.$ photons $\left.\mathrm{m}^{-2} \mathrm{~s}^{-1}\right)$ for $48 \mathrm{~h}$ (Figure 5). A 70-microliter aliquot was put in a 96-well plate and pictured. The cell density of each well was quantified using Image $\mathrm{J}$ in Figure 5.

\subsection{Photosynthetic Parameter Analyses}

The chlorophyll amount of the cell culture in an HS medium was measured, and cell density was adjusted to ensure that the cells contain $2.5 \mu \mathrm{g} / \mathrm{mL}$ chlorophyll. Chlorophyll fluorescence-based photosynthetic analysis was performed as follows. Maximum yields (Fm) were measured under dark conditions (after weak far-red $\left(<5 \mu\right.$ mol photons $\mathrm{m}^{-2}$ $\mathrm{s}^{-1}$ ) treatment for 30 min using Dual-PAM (WALZ, Germany) for Table 2 or Imaging PAM (WALZ, Germany) for Figure 4. Following the method of [39], the maximum and steady-state fluorescence yields under light ( $\mathrm{Fm}^{\prime}$ and $\mathrm{F}$, respectively) were measured after actinic irradiation at each light intensity for $90 \mathrm{~s}$. The effective PSII quantum yield $Y($ II) (or $\varphi \mathrm{II})$ was estimated using the equation, $\mathrm{Y}(\mathrm{II})=\left(\mathrm{Fm}^{\prime}-\mathrm{F}\right) / \mathrm{Fm}^{\prime}$. Nonphotochemical quenching capability $(\mathrm{NPQ})$ was estimated using the equation, $\mathrm{NPQ}=\left(\mathrm{Fm}-\mathrm{Fm}^{\prime}\right) / \mathrm{Fm}^{\prime}$. The ETR was estimated using ETR $=\mathrm{Y}(\mathrm{II}) \times 0.84 \times 0.5 \times$ light intensity.

\subsection{PCR against Tetrad Progenies}

Tetrad progenies were subjected to PCR to determine the presence of the APHVIII gene using the method of [40].

Supplementary Materials: The following are available online at https:/ /www.mdpi.com/article/10 .3390/plants10071483/s1, Figure S1: Tetrad analysis to test linkage between phenotype and genotype.

Author Contributions: Conceptualization: J.M. (Jun Minagawa), T.H., and K.-i.W.; investigation and data curation: J.M. (Jun Morishita), R.T., and K.-i.W.; writing: J.M. (Jun Morishita), R.T., and K.-i.W.; supervision: J.M. (Jun Minagawa), T.H., and K.-i.W.; project administration: K.-i.W.; funding acquisition: R.T., T.H., and K.-i.W. All authors have read and agreed to the published version of the manuscript.

Funding: Funding was provided by grants from JSPS KAKENHI [15H05599 and 20H03282 to R.T., 16H06556 to T.H., and 19H03242, 20K21420, and 21H00420 to K.-i.W.], Ohsumi Frontier Science Foundation to K.-i.W., and by Dynamic Alliance for Open Innovation Bridging Human, Environment, and Materials to T.H. and K.-i.W.

Institutional Review Board Statement: Not applicable.

Informed Consent Statement: Not applicable.

Data Availability Statement: The data presented in this study are available in this article or supplementary material.

Acknowledgments: The authors thank Keisuke Yoshida (Tokyo Tech) for the help in the PAM analysis and Masako Nakajima, Yuichiro Hoga (Tokyo Tech), and Noriko Ueki (Hosei Univ) for the help in the mutant screening.

Conflicts of Interest: The authors declare that they have no conflict of interest.

\section{References}

1. Wakabayashi, K.; Isu, A.; Ueki, N. Channelrhodopsin-dependent photo-behavioral responses in the unicellular green alga Chlamydomonas reinhardtii. Adv. Exp. Med. Biol. 2021, 1293, 21-33.

2. Harris, E.H. Motility and behavior. In The Chlamydomonas Sourcebook, 2nd ed.; Academic Press: Cambridge, MA, USA, 2009; Volume 1, pp. 89-117.

3. Hartshorne, J.N. The function of the eyespot in Chlamydomonas. New Phytol. 1953, 52, 292-297. [CrossRef]

4. Dieckmann, C.L. Eyespot placement and assembly in the green alga Chlamydomonas. BioEssays 2003, 25, 410-416. [CrossRef] [PubMed] 
5. Foster, K.W.; Smyth, R.D. Light Antennas in phototactic algae. Microbiol. Rev. 1980, 44, 572-630. [CrossRef]

6. Morel-Laurens, N.M.L.; Feinleib, M.E.H. Photomovement in an "eyeless" mutant of Chlamydomonas. Photochem. Photobiol. 1983, 37, 189-194. [CrossRef]

7. Ueki, N.; Ide, T.; Mochiji, S.; Kobayashi, Y.; Tokutsu, R.; Ohnishi, N.; Yamaguchi, K.; Shigenobu, S.; Tanaka, K.; Minagawa, J.; et al. Eyespot-dependent determination of the phototactic sign in Chlamydomonas reinhardtii. Proc. Natl. Acad. Sci. USA 2016, 113, 5299-5304. [CrossRef]

8. Nagel, G.; Ollig, D.; Fuhrmann, M.; Kateriya, S.; Musti, A.M.; Bamberg, E.; Hegemann, P. Channelrhodopsin-1: A light-gated proton channel in green algae. Science 2002, 296, 2395-2398. [CrossRef] [PubMed]

9. Nagel, G.; Szellas, T.; Huhn, W.; Kateriya, S.; Adeishvili, N.; Berthold, P.; Ollig, D.; Hegemann, P.; Bamberg, E. Channelrhodopsin-2, a directly light-gated cation-selective membrane channel. Proc. Natl. Acad. Sci. USA 2003, 100, 13940-13945. [CrossRef]

10. Nagel, G.; Szellas, T.; Kateriya, S.; Adeishvili, N.; Hegemann, P.; Bamberg, E. Channelrhodopsins: Directly light-gated cation channels. Biochem. Soc. Trans. 2005, 33, 863-866. [CrossRef]

11. Kamiya, R.; Witman, G.B. Submicromolar levels of calcium control the balance of beating between the two flagella in demembranated models of Chlamydomonas. J. Cell Biol. 1984, 98, 97-107. [CrossRef] [PubMed]

12. Feinleib, M.E.H.; Curry, G.M. The relationship between stimulus intensity and oriented phototactic response (topotaxis) in Chlamydomonas. Physiol. Plant 1971, 25, 346-352. [CrossRef]

13. Morel-Laurens, N. Calcium control of phototactic orientation in Chlamydomonas reinhardtii: Sign and strength of response. Photochem. Photobiol. 1987, 45, 119-128. [CrossRef] [PubMed]

14. Takahashi, T.; Watanabe, M. Photosynthesis modulates the sign of phototaxis of wild-type Chlamydomonas reinhardtii. Effects of red background illumination and 3-(3',4'-dichlorophenyl)-1,1-dimethylurea. FEBS Lett. 1993, 336, 516-520. [CrossRef]

15. Wakabayashi, K.; Misawa, Y.; Mochiji, S.; Kamiya, R. Reduction-oxidation poise regulates the sign of phototaxis in Chlamydomonas reinhardtii. Proc. Natl. Acad. Sci. USA 2011, 108, 11280-11284. [CrossRef]

16. Ide, T.; Mochiji, S.; Ueki, N.; Yamaguchi, K.; Shigenobu, S.; Hirono, M.; Wakabayashi, K. Identification of the agg1 mutation responsible for negative phototaxis in a "wild-type" strain of Chlamydomonas reinhardtii. Biochem. Biophys. Rep. 2016, 7, 379-385. [CrossRef]

17. Demmig-Adams, B.; Adams, W.W. 3rd Photoprotection and other responses of plants to high light stress. Annu. Rev. Plant Physiol. Plant Mol. Biol. 1992, 43, 599-626. [CrossRef]

18. Niyogi, K.K. Photoprotection Revisited: Genetic and molecular approaches. Annu. Rev. Plant Physiol. Plant Mol. Biol. 1999, 50, 333-359. [CrossRef] [PubMed]

19. Zhao, L.; Xie, H.; Kang, Y.; Lin, Y.; Liu, G.; Sakato-Antoku, M.; Patel-King, R.S.; Wang, B.; Wan, C.; King, S.M.; et al. Heme-binding protein CYB5D1 is a radial spoke component required for coordinated ciliary beating. Proc. Natl. Acad. Sci. USA 2021, 118, e2015689118. [CrossRef]

20. Böhm, M.; Boness, D.; Fantisch, E.; Erhard, H.; Frauenholz, J.; Kowalzyk, Z.; Marcinkowski, N.; Kateriya, S.; Hegemann, P.; Kreimer, G. Channelrhodopsin-1 phosphorylation changes with phototactic behavior and responds to physiological stimuli in Chlamydomonas. Plant Cell 2019, 31, 886-910. [CrossRef]

21. Sizova, I.; Fuhrmann, M.; Hegemann, P. A Streptomyces rimosus aphVIII gene coding for a new type phosphotransferase provides stable antibiotic resistance to Chlamydomonas reinhardtii. Gene 2001, 277, 221-229. [CrossRef]

22. Wakabayashi, K.; King, S.M. Modulation of Chlamydomonas reinhardtii flagellar motility by redox poise. J. Cell Biol. 2006, 173, 743-754. [CrossRef]

23. Petroutsos, D.; Tokutsu, R.; Maruyama, S.; Flori, S.; Greiner, A.; Magneschi, L.; Cusant, L.; Kottke, T.; Mittag, M.; Hegemann, P.; et al. A blue-light photoreceptor mediates the feedback regulation of photosynthesis. Nature 2016, 537, 563-566. [CrossRef]

24. Allorent, G.; Lefebvre-Legendre, L.; Chappuis, R.; Kuntz, M.; Truong, T.B.; Niyogi, K.K.; Ulm, R.; Goldschmidt-Clermont, M. UV-B photoreceptor-mediated protection of the photosynthetic machinery in Chlamydomonas reinhardtii. Proc. Natl. Acad. Sci. USA 2016, 113, 14864-14869. [CrossRef]

25. Sirikhachornkit, A.; Shin, J.W.; Baroli, I.; Niyogi, K.K. Replacement of alpha-tocopherol by beta-tocopherol enhances resistance to photooxidative stress in a xanthophyll-deficient strain of Chlamydomonas reinhardtii. Eukaryot Cell 2009, 8, 1648-1657. [CrossRef] [PubMed]

26. Dent, R.M.; Haglund, C.M.; Chin, B.L.; Kobayashi, M.C.; Niyogi, K.K. Functional genomics of eukaryotic photosynthesis using insertional mutagenesis of Chlamydomonas reinhardtii. Plant Physiol. 2005, 137, 545-556. [CrossRef] [PubMed]

27. Fischer, B.B.; Ledford, H.K.; Wakao, S.; Huang, S.G.; Casero, D.; Pellegrini, M.; Merchant, S.S.; Koller, A.; Eggen, R.I.; Niyogi, K.K. Singlet oxygen RESISTANT 1 links reactive electrophile signaling to singlet oxygen acclimation in Chlamydomonas reinhardtii. Proc. Natl. Acad. Sci. USA 2012, 109, E1302-E1311. [CrossRef]

28. Zhang, M.P.; Wang, M.; Wang, C. Nuclear transformation of Chlamydomonas reinhardtii: A review. Biochimie 2021, 181, 1-11. [CrossRef]

29. Dayer, R.; Fischer, B.B.; Eggen, R.I.; Lemaire, S.D. The peroxiredoxin and glutathione peroxidase families in Chlamydomonas reinhardtii. Genetics 2008, 179, 41-57. [CrossRef] [PubMed]

30. Murchie, E.H.; Ruban, A.V. Dynamic non-photochemical quenching in plants: From molecular mechanism to productivity. Plant J. 2020, 101, 885-896. [CrossRef] 
31. Baroli, I.; Do, A.D.; Yamane, T.; Niyogi, K.K. Zeaxanthin accumulation in the absence of a functional xanthophyll cycle protects Chlamydomonas reinhardtii from photooxidative stress. Plant Cell 2003, 15, 992-1008. [CrossRef] [PubMed]

32. Fischer, B.B.; Eggen, R.I.; Niyogi, K.K. Characterization of singlet oxygen-accumulating mutants isolated in a screen for altered oxidative stress response in Chlamydomonas reinhardtii. BMC Plant Biol. 2010, 10, 279. [CrossRef]

33. Tokutsu, R.; Fujiwara-Kamada, K.; Matsuo, T.; Yamasaki, T.; Minagawa, J. The CONSTANS flowering complex controls the prote4ctive response of photosynthesis in the green alga Chlamydomonas. Nat Commun. 2019, 10, 4099. [CrossRef] [PubMed]

34. Gorman, D.S.; Levine, R.P. Cytochrome $\mathrm{f}$ and plastocyanin: Their sequence in the photosynthetic electron transport chain of Chlamydomonas reinhardi. Proc. Natl. Acad. Sci. USA 1965, 54, 1665-1669. [CrossRef] [PubMed]

35. Sueoka, N. Mitotic replication of deoxyribonucleic acid in Chlamydomonas Reinhardi. Proc. Natl. Acad. Sci. USA 1960, 46, 83-91. [CrossRef] [PubMed]

36. Yamano, T.; Iguchi, H.; Fukuzawa, H. Rapid transformation of Chlamydomonas reinhardtii without cell-wall removal. J. Biosci. Bioeng. 2013, 115, 691-694. [CrossRef]

37. Kamiya, R. Analysis of cell vibration for assessing axonemal motility in Chlamydomonas. Methods 2000, 22, 383-387. [CrossRef]

38. Porra, R.J.; Thompson, W.A.; Kriedemann, P.E. Determination of accurate extinction coefficients and Simultaneous equations for assaying chlorophylls a and $\mathrm{b}$ extracted with four different solvents: Verification of the concentration of chlorophyll standards by atomic absorption spectroscopy. Biochim. Biophys. Acta Bioenerg. 1989, 975, 384-394. [CrossRef]

39. Dang, K.V.; Plet, J.; Tolleter, D.; Jokel, M.; Cuiné, S.; Carrier, P.; Auroy, P.; Richaud, P.; Johnson, X.; Alric, J.; et al. Combined increases in mitochondrial cooperation and oxygen photoreduction compensate for deficiency in cyclic electron flow in Chlamydomonas reinhardtii. Plant Cell. 2014, 26, 3036-3050. [CrossRef]

40. Cao, M.; Fu, Y.; Guo, Y.; Pan, J. Chlamydomonas (Chlorophyceae) colony PCR. Protoplasma 2009, 235, 1. [CrossRef] 